\title{
Interactive effects of agile response-to-change and project complexity on project performance
}

\author{
Tuan Son Nguyen ${ }^{1}$ and Sherif Mohamed ${ }^{2}$
}

\begin{abstract}
Complexity is a critical factor in managing a project, as it presents an additional difficulty in achieving the project's objectives. As complexity makes a project more challenging to understand and keep under control, agile methodologies have been developed to enable increased flexibility and responsiveness to changing conditions. Therefore, it is essential to empirically examine the moderating effect of project complexity on the relationship between agile response-to-change (AR) and project performance. To address this objective, a questionnaire was used to measure project complexity, project performance and AR. Structural equation modelling was used to explore the relationship between these variables. The results suggested that internal AR has a positive effect on budget performance. Project complexity appears to lower the relationship between internal AR and schedule performance. As one would expect, the higher the level of project complexity, the more likely the project is to experience delays.
\end{abstract}

Keywords: Agile response-to-change, project complexity, project performance.

\section{Introduction}

It is widely reported in the literature that many projects fail (Damoah and Akwei, 2017). Many reasons can lead to project failure, and complexity is one such reason, as it creates difficulty in finishing projects and requires more effort be devoted to overcoming challenges (Dao et al., 2016). Complex projects are susceptible to running over budget and behind schedule (Lu et al., 2015; Bjorvatn and Wald, 2018). Time and budget are two of the main criteria used to evaluate project performance (PMI, 2008). Bosch-Rekveldt et al. (2011) found that project complexity negatively affects project performance in large engineering projects. Furthermore, Floricel et al. (2016) found that complexity factors were correlated with a reduction in completion performance, where completion performance was measured as whether a project achieved its planned resource expenditures and deadlines. For instance, the 2A line metro project in Hanoi, Vietnam, began in 2011 and was scheduled to commence commercial operation in 2016, with an initial budget of about 550 million dollars. However, in early 2019, the project is still not operating commercially and is approximately $40 \%$ over budget (Kieu, 2018).

To overcome the challenge of project complexity, many project management strategies have been proposed to mitigate the negative effect of complexity. AR is one of the practical strategies used to deal with complexity in projects. Agile methodologies were designed to enable greater flexibility and responsiveness to the changing conditions in a project to improve project performance (Fowler and Highsmith, 2001). Agile

1 HDR Candidature, School of Engineering and Built Environment, Griffith University, Australia, Email: tuanson.nguyen@griffithuni.edu.au

2 Professor, Head of School, School of Engineering and Built Environment, Griffith University, Australia, Email: s.mohamed@griffith.edu.au 
methodologies are commonly applied for managing complex projects (Lappi and Aaltonen, 2017). Moreover, Serrador and Pinto (2015) suggested that the higher the agile approach reported, the better the reported project performance.

The concept of AR and its effects on project performance have been discussed by Nguyen and Mohamed (2018b). However, little research has been undertaken to empirically examine the effect of AR and project complexity on quantitative project performance (time and cost). It remains unclear whether a project with a higher level of AR sustains its quantitative project performance under changing levels of project complexity. Therefore, this study aims to examine the interactive effects of AR and project complexity on project performance. It investigated the moderating effect of project complexity on the relationship between AR and project performance.

\section{Literature Review and Hypothesis Development}

This section presents the literature related to project performance, project complexity and AR. Following this, a conceptual framework and a set of hypotheses are proposed.

\section{Project Performance}

Indicators for project performance measurement are well established, and include time, budget and performance goals (Shenhar et al., 2001). The Project Management Body of Knowledge (PMBOK) refers to project performance with regard to time, cost, quality, scope and customer satisfaction (PMI, 2008); commonly known as the 'triple constraint'. Project performance is evaluated depending on achieving the project's objectives within the constraints of time, cost, quality and other project achievement requirements (Ika, 2009).

Project performance measurement indicators can be grouped into different components. Serrador and Pinto (2015) classified project performance indicators into two groups; namely, efficiency factors and stakeholder success factors. The efficiency factor indicators include project scope, time and budget. The stakeholder success factor indicators include project team satisfaction, end user satisfaction, client satisfaction and project success as evaluated by stakeholders. It can be seen that the stakeholder satisfaction indicators are separate from project time, budget and scope. However, the efficiency measurement indicators have both quantitative measurement items (time and cost) and qualitative project measurement items (project scope). Using both quantitative and qualitative project performance measurement indicators as one component may raise issues, since time and budget are precise criteria in comparison with project scope criteria. Consequently, project performance indicators can be classified into different components, such as quantitative project performance and qualitative project performance (Nguyen and Mohamed, 2018a).

\section{Project Complexity}

In the context of complex projects, 'complexity' refers to 'the property of a project which makes it difficult to understand, foresee and keep under control its overall behaviour, even when given reasonable complete information about the project system' (Vidal et al., 2011). In theoretical terms, project complexity depends on both the characteristics of the project and the capacity of project management teams to tackle the diverse factors that influence project outcomes (Nguyen et al., 2018). Since complexity refers to an intrinsic property of projects (Floricel et al., 2016), scholars have attempted to quantify and measure it (Vidal et al., 2011); and studies on project complexity have been undertaken for years (Aitken and Crawford, 2007; Vidal et al., 2011; Dao et al., 2017). One of the primary project 
classification methods applied by institutions in the project management field (BoschRekveldt et al., 2011) is the Crawford-Ishikura seven-factor table for evaluating roles (CIFTER) (GAPPS, 2007).

Although complexity is an intrinsic property of a project (Floricel et al., 2016), the influence of complexity on project performance has not been extensively studied in empirical terms (Bjorvatn and Wald, 2018). Bakhshi et al. (2016) stated that complexity is one of the most highly controversial topics in the management field. Project complexity has been reported as the main factor having a negative effect on project performance (Floricel et al., 2016; Luo et al., 2017). Project complexity negatively influences project success in complex construction projects (Luo et al., 2017). A negative statistical correlation between technical complexity and budget and schedule performance had been identified by Floricel et al. (2016). Project teams encounter a greater risk of running behind time and over budget as the number of internal and external project tasks increases.

\section{Agile Response to Change}

The concept of agile methodology was proposed by 17 experts in the USA in 2001; and is widely known as the 'Agile Manifesto' (Fowler and Highsmith, 2001). Four foundation values of agile development were recommended in the Manifesto. These are i) 'Individuals and interactions over processes and tools'; ii) 'Working software over comprehensive documentation'; iii) 'Customer collaboration over contract negotiation'; and iv) 'Responding to change over following a plan' (Fowler and Highsmith, 2001).

Agile methods are commonly applied in technology projects (Lindvall et al., 2002) as they directly tackle the challenges associated with dynamic projects in rapidly changing environments (Serrador and Pinto, 2015). The project management team's ability to respond to these difficulties plays an essential role in managing project success or failure (Park et al., 2017). AR is one of the critical components in the stakeholder management framework for mega construction projects (Park et al., 2017). Serrador and Pinto (2015) reported that the higher the agile method used, the better the project performance. In order to add to this discussion, the correlation between AR and project performance, in particular regarding budget and schedule, should be empirically studied.

\section{Conceptual Model and Hypothesis Development}

As discussed in the previous section, AR plays a critical role in the context of complex projects. Agile methodologies may have a positive effect on project performance; especially in preventing running over budget and behind schedule. However, project complexity is one of the sources that influence project performance. The positive effect of $\mathrm{AR}$ on project time and cost is more likely to be moderated by the complexity of the projects. Thus, the following hypotheses are proposed:

Hypothesis 1: AR has a positive effect on quantitative project performance.

Hypothesis 2: Project complexity lowers the positive correlation between AR and quantitative project performance.

Figure 1 depicts the research model. 


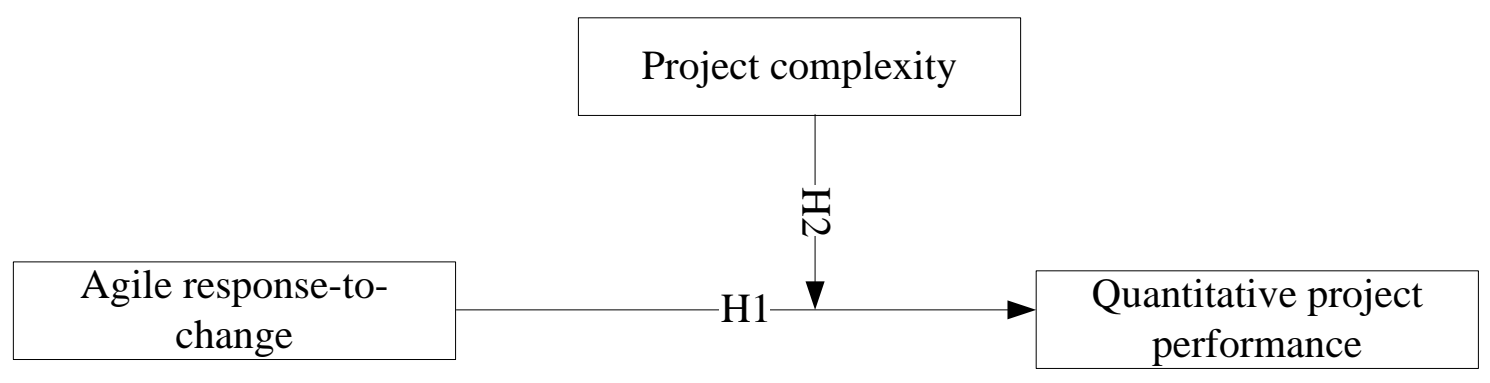

Figure 1. Research model

\section{Research Methodology}

\section{Construct Operationalisation}

This study was a cross-sectional design study with quantitative research using survey questionnaire to gather data. Guided by the research model, in this study, three constructs, namely project complexity, quantitative project performance and AR, were operationalised. Each measurement indicator for the individual constructs was adopted from previous studies.

Project complexity. CIFTER has been adopted to evaluate the level of project complexity. Project complexity is estimated by how each of these factors is assessed in comparison with its level in an 'average' project. In the survey, respondents were requested to consider a recently finished project undertaken by their organisation and were required to compare their selected project with the average project with respect to the CIFTER factors. The total score of these factors estimates the level of project complexity. Higher scores determine a greater level of project complexity.

Quantitative project performance. The quantitative project performance indicators are the project's time and cost. A five-point Likert scale (1-5) was used to measure each criterion. Higher scores refer to better performance.

$A R$. This study used six items to operationalise AR. The first four items were adopted from (Park et al., 2017), and the remaining two items were proposed based on the project complexity characteristics (Baccarini, 1996; Floricel et al., 2016). A five-point Likert scale (1-5) was used to measure each criterion. Higher scores indicate a better level of AR.

\section{Data Collection and Data Analysis}

Data were collected using an online survey. The target participants were either a project manager or a project team member of any projects. The online survey was distributed via a link through email, Australian Institute of Project Management, Project Management Institute, and social media. There were 436 participants who accessed the survey, which 234 completed. In total, 136 sets of responses were proven valid for the final data analysis.

Structural equation modelling (SEM) was applied for the data analysis as it is commonly applied in social science research (Bryman and Bell, 2015). Confirmatory factor analysis was used to assess a measurement model. SEM was used to examine the structural model, which assessed the relationship between AR and quantitative project performance and the moderating effect of project complexity. The model fit indices were used to evaluate the adequacy of the model fit (Kline, 2015). 


\section{Results}

\section{Validity and Reliability Analysis}

Cronbach's alpha was calculated to evaluate the reliability of the measurement constructs. The Cronbach's alpha values of the measurement scales were at an acceptable level, with the project complexity construct $(\alpha=0.683$ ) very close to the suggested value of 0.70 and the AR value $(\alpha=0.785)$ higher than suggested level, thereby indicating the reliability of the constructs.

To developing a reduced set of components from the six-item questionnaire assessing $\mathrm{AR}$, the data collected from 136 participants were subjected to principal component analysis factoring with varimax rotation. Two factors (with eigenvalues exceeding 1) were identified as underlying the six questionnaire items. These two factors were derived from the six items for internal AR and external AR (Appendix A).

\section{Structural Model Analysis}

To test the hypotheses, SEM was used to assess the correlation between AR and quantitative project performance. Figure 2 presents the direct effect testing model. The results indicated that there was a significant and positive correlation between internal AR $\left(\mathrm{AR}_{\text {int }}\right)$ and budget performance $(\mathrm{BP})(\beta=0.229, \mathrm{t}$-value $=2.042, \mathrm{p}=0.041)$. No significant effect was observed between (i) internal and external AR and schedule performance (SP); (ii) external $\mathrm{AR}\left(\mathrm{AR}_{\mathrm{ext}}\right)$ and $\mathrm{BP}$. Therefore, the $\mathrm{H} 1$ should be revised:

H1: Internal AR has a positive effect on BP.

SEM was applied for interactive effect testing. In this study, the two-way interaction was examined (Dawson, 2014). Figure 3 presents the interactive effect testing model. There was a significant negative correlation between the interaction effect ( $\mathrm{PC}^{*} \mathrm{AR}$ int $)$ and SP $(\beta=-0.277, \mathrm{t}$-value $=-2.736, \mathrm{p}=0.006)$. No significant correlation was observed between (i) interaction effect $\left(\mathrm{PC}^{*} \mathrm{AR}\right.$ int $)$ and $\mathrm{BP}$; (ii) interaction effect $\left(\mathrm{PC}^{*} \mathrm{AR}\right.$ ext $)$ and $\mathrm{SP}$ and $\mathrm{BP}$. Therefore, the $\mathrm{H} 2$ should be revised:

H2: Project complexity lowers the positive correlation between internal AR and SP.

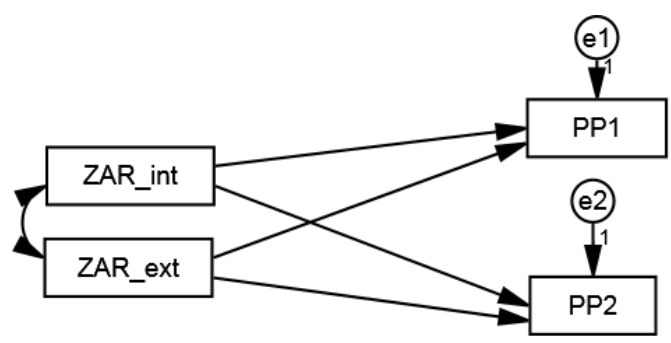

Note: $\mathrm{PP} 1=\mathrm{SP} ; \mathrm{PP} 2=\mathrm{BP}$

Figure 2. Direct effect testing model

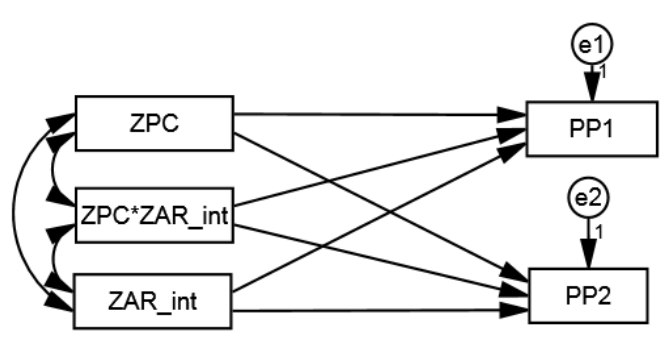

Figure 3. Interactive effect testing model

\section{Discussion and Conclusion}

Internal AR was measured via assessment of the capacity of project management teams to adapt to changes in technology and rapidly changing tasks in a project (Appendix A). As anticipated in $H 1$, the results showed that internal AR is positively correlated with $\mathrm{BP}(\beta=$ $0.229, \mathrm{t}$-value $=2.042, \mathrm{p}=0.041)$. This result suggests that improving the capacity of project management teams to respond to changes in tasks and technology may help to prevent or mitigate project delays. This finding is reinforced by that of Serrador and Pinto 
(2015), who state that the better the agile approach report, the better the project performance. However, the regression weight for external AR in the prediction of both BP and SP was not statistically significant at the 0.05 level. This result suggests that project management teams should pay more attention to improving their capacity to respond to internal changes rather than external changes.

As anticipated in $H 2$, the results of the study indicate that the effect of internal AR on SP does not remain constant at different levels of project complexity. The results of the interaction analysis show that project complexity negatively moderates the influence of internal AR on SP. Our finding is consistent with previous results showing that project complexity acts as a moderator and interferes in the relationship between certain independent variables and dependent variables (Açıkgöz et al., 2016). For example, project complexity negatively moderates the relationship between knowledge exploitation and new product development (Açıkgöz et al., 2016). In the context of complex projects, where dynamic and uncertain environments exist; it is reasonable to assume that overcoming these difficulties will take time while the quality of the project is maintained.

In conclusion, this study makes a significant contribution to the existing literature by empirically examining the relationship between AR and quantitative project performance, and the moderating effect of project complexity on this relationship. First, this study has revealed that internal AR positively affects BP. However, project complexity reduces the effect of internal AR on SP. These findings suggested that internal AR might help to prevent over-budget in the context of complex projects. Whereas, the effect of internal AR on mitigating delay might not be the same when the level of project complexity increases. This implies that BP relies on the ability to respond to internal changes. The best option for a project management team is thus to reduce the level of project complexity and thereby enhance the capacity to respond to rapidly changing project tasks and technological changes.

The current study finding also suggests that project managers should pay more attention to improving their ability to respond to internal changes like changing project tasks and technological changes rather than external changes - such as political, economic, policy and social value changes.

This study conducted a quantitative approach that focuses on testing theories. Therefore, it might not take a view of social reality as constantly changing; therefore, the current practices might slightly differ from the theories. This can be seen as a limitation of the study.

This study only examined the relationship between AR and project time and budget. The future study might discover the relationship between AR and qualitative project performance, such as stakeholder satisfaction and other business values, in the context of complex projects. 
Appendix A. Measurement of Constructs

\begin{tabular}{ll}
\hline Construct & Items \\
\hline PP $_{\text {qn }}$ & Quantitative project performance \\
& PP1: Extent to which the project was delivered on schedule \\
PP2: Extent to which the project was delivered on budget \\
Project compexity \\
PC1: Number of different organisations involved in the project \\
PC2: Number of distinct disciplines, methods, or approaches involved in \\
project execution \\
PC3: Level of stakeholder agreement about the project outcomes \\
PC4: Level of importance of legal, social, or environmental implications on \\
project execution \\
PC5: Overall financial impact (positive or negative) on the project's \\
stakeholders \\
PC6: Level of importance of the project to my organisation \\
PC7: Level of stability of the overall project context \\
Agile response-to-change \\
AR1: Project management team had the abilities to respond to political \\
changes that affected the project \\
AR2: Project management team had the abilities to respond to economic \\
changes that affected the project \\
AR3: Project management team had the abilities to respond to policy changes \\
that affected the project \\
AR4: Project management team had the abilities to respond to social value \\
changes (e.g. awareness of environmental issues, safety standard and climate \\
change) that affected the project \\
AR5: Project management team had the abilities to respond to technology \\
changes that affected the project \\
AR6: Project management team had the abilities to respond to rapidly \\
changing tasks in the project
\end{tabular}

Note: *: Sub-constructs. $\mathrm{AR}_{\text {ext }}$ : External agile response-to-change. $\mathrm{AR}_{\text {int }}$ Internal agile response-to-change.

\section{Reference}

Açıkgöz, A., Günsel, A., Kuzey, C., and Seçgin, G., 2016. Functional Diversity, Absorptive Capability and Product Success: The Moderating Role of Project Complexity in New Product Development Teams: Functional Diversity, Absorptive Capability and Product Success. Creativity and Innovation Management, 25(1), 90-109.

Aitken, A., and Crawford, L., 2007. A study of project categorisation based on project management complexity. Paper presented at the IRNOP VIII Conference (8th Annual International Research Network on Organizing by Projects).

Baccarini, D., 1996. The concept of project complexity-a review. International Journal of Project Management, 14(4), 201-204.

Bakhshi, J., Ireland, V., and Gorod, A., 2016. Clarifying the project complexity construct: Past, present and future. International Journal of Project Management, 34(7), 11991213.

Bjorvatn, T., and Wald, A., 2018. Project complexity and team-level absorptive capacity as drivers of project management performance. International Journal of Project Management, 36(6), 876-888. 
Bosch-Rekveldt, M., Jongkind, Y., Mooi, H., Bakker, H., and Verbraeck, A., 2011. Grasping project complexity in large engineering projects: The TOE (Technical, Organizational and Environmental) framework. International Journal of Project Management, 29(6), 728-739.

Bryman, A., and Bell, E., 2015. Business research methods (Fourth ed.). New York, NY, United States of America;Cambridge, United Kingdom;: Oxford University Press.

Damoah, I. S., and Akwei, C., 2017. Government project failure in Ghana: a multidimensional approach. International Journal of Managing Projects in Business, 10(1), 32-59.

Dao, B., Kermanshachi, S., Shane, J., Anderson, S., and Hare, E., 2016. Identifying and Measuring Project Complexity. Procedia Engineering, 145, 476-482.

Dao, B., Kermanshachi, S., Shane, J., Anderson, S., and Hare, E., 2017. Exploring and Assessing Project Complexity. Journal of Construction Engineering and Management, 143(5).

Dawson, J. F., 2014. Moderation in Management Research: What, Why, When, and How. Journal of Business and Psychology, 29(1), 1-19.

Floricel, S., Michela, J. L., and Piperca, S., 2016. Complexity, uncertainty-reduction strategies, and project performance. International Journal of Project Management.

Fowler, M., and Highsmith, J., 2001. The Agile Manifesto. Software Development, 9(8), 7.

GAPPS., 2007. Global Alliance for Project Performance Standards.

Ika, L. A., 2009. Project Success as a Topic in Project Management Journals. Project Management Journal, 40(4), 6-19.

Kieu, L., 2018. Duong sat Cat Linh - Ha Dong. Retrieved 26 Mar 2019 http://vneconomy.vn/duong-sat-cat-linh-ha-dong-moi-nam-tra-no-trung-quoc-khoang650-ty-20180122162846335.htm

Kline, R. B., 2015. Principles and practice of structural equation modeling: Guilford publications.

Lappi, T., and Aaltonen, K., 2017. Project governance in public sector agile software projects. International Journal of Managing Projects in Business, 10(2), 263-294.

Lindvall, M., Basili, V., Boehm, B., Costa, P., Dangle, K., Shull, F., and Zelkowitz, M., 2002. Empirical Findings in Agile Methods. Extreme Programming and Agile MethodsXP/Agile Universe, 81-92.

Lu, Y., Luo, L., Wang, H., Le, Y., and Shi, Q., 2015. Measurement model of project complexity for large-scale projects from task and organization perspective. International Journal of Project Management, 33(3), 610-622.

Luo, L., He, Q. H., Xie, J. X., Yang, D. L., and Wu, G. D., 2017. Investigating the Relationship between Project Complexity and Success in Complex Construction Projects. Journal of Management in Engineering, 33(2).

Nguyen, T. S., and Mohamed, S., 2018a. Exploring the Relationship between Stakeholder Characteristics and Project Performance. Paper presented at the 1st International Conference on Construction Project Management and Construction Engineering (iCCPMCE-2018), Sydney, Australia. 
Nguyen, T. S., and Mohamed, S., 2018b. Stakeholder Management in Complex Projects. Paper presented at the The 7th World Construction Symposium 2018: Built Asset Sustainability: Rethinking Design, Construction and Operations, Colombo, Sri Lanka.

Nguyen, T. S., Mohamed, S., and Panuwatwanich, K., 2018. Stakeholder Management in Complex Project: Review of Contemporary Literature. Journal of Engineering, Project, and Production Management, 8(2), 75-89.

Park, H., Kim, Y.-W., Kim, H., and Kim, K., 2017. Stakeholder Management in LongTerm Complex Megaconstruction Projects: The Saemangeum Project. Journal of Management in Engineering, 33(4), 5017002.

PMI., 2008. A guide to the project management body of knowledge (PMBOK guide) (Vol. 4th;Fourth;). Newtown Square, Pa: Project Management Institute, Inc.

Serrador, P., and Pinto, J. K., 2015. Does Agile work? - A quantitative analysis of agile project success. International Journal of Project Management, 33(5), 1040-1051.

Shenhar, A. J., Dvir, D., Levy, O., and Maltz, A. C., 2001. Project Success: A Multidimensional Strategic Concept. Long Range Planning, 34(6), 699-725.

Vidal, L.-A., Marle, F., and Bocquet, J.-C., 2011. Measuring project complexity using the Analytic Hierarchy Process. International Journal of Project Management, 29(6), 718727. 